\title{
Science Data in Support of Environmental Health Studies in the U.S.-Mexico Border Region
}

Background: The border region of the United States and Mexico encompasses a vast and diverse array of physical settings and habitats that include wetlands, deserts, rangeland, mountains, and forests, which are unique in terms of the diversity of their water, mineral, and biological resources. The region is interconnected economically, politically, and socially owing to its binational heritage. In 1995, nearly 11 million people lived immediately adjacent to the border. By one account, that population could more than double by 2020 .

This rapid population growth and consequent economic development and land-use changes are pushing the limits of environmental sustainability and quality. Infrastructure development has lagged behind the rapid growth of the region, resulting in a shortage of water for municipal, agricultural, and industrial uses. These stressors threaten the quality of life in the region and raise concerns about the interdependence of environmental quality and human health.

To allow for continued economic growth while protecting the area's natural resources and fostering a high quality of life, the United States and Mexico need an improved understanding of the threats posed by these anthropogenic changes.

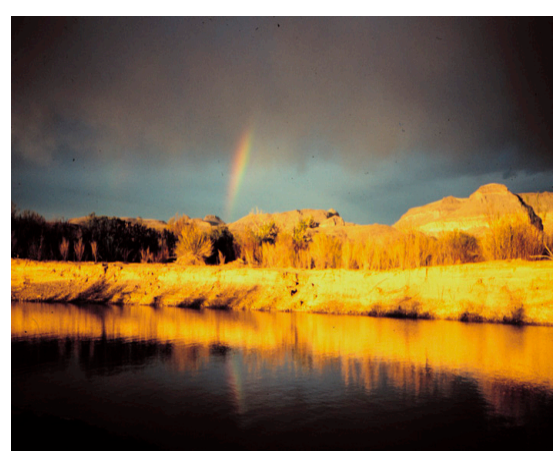

Figure 1. Rio Grande/Rio Bravo.

Issues of particular concern include (1) contaminants in ground water, surface water, and biota from agricultural, municipal, and industrial activities; (2) airborne pollutants from fossil-fuel combustion and other activities; (3) contaminants from past and present mining activities and mineral deposits; and

(4) pathogens, pharmaceuticals, hormones, and other contaminants released in treated and untreated human and animal wastewaters.

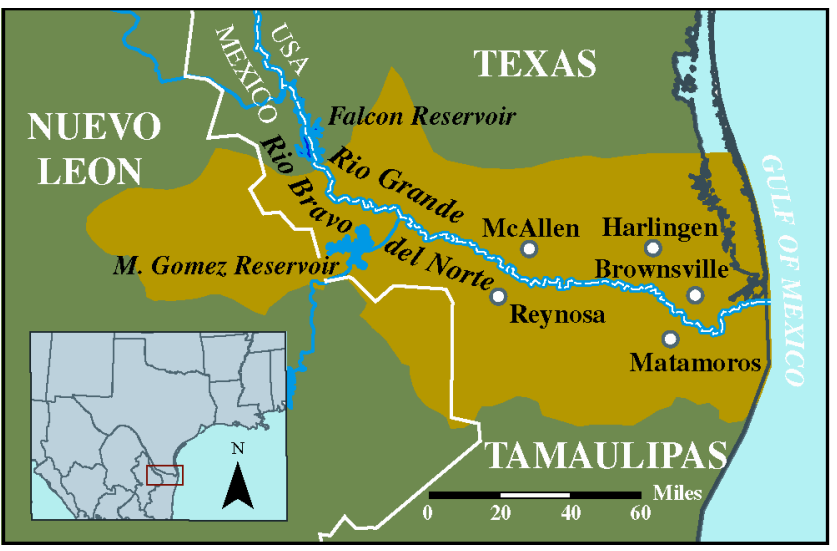

Figure 2. Study area.
Geographic Extent: The project ultimately will encompass the entire U.S.-Mexico border region. Work in 2004 will focus on watersheds and aquifers along the Rio Grande/Rio Bravo below Falcon Reservoir and extend to the lower part of the Laguna Madre of Texas and the nearshore parts of the Gulf of Mexico. The region encompasses 10,240 square miles-6,155 in Mexico and 4,085 in the United States. In Texas, the primary population centers are McAllen, Harlingen, and Brownsville; in Tamaulipas, they are Reynosa and Matamoros. Among the unique habitats of this segment of the international border region are the resacas (oxbow lakes) of the Lower Rio Grande Valley. As in other border areas, the water resources and associated plants, fish, and wildlife of the Lower Rio Grande Valley are increasingly subject to the effects of human activities.

Science Objective:

The primary objective of this project is to develop an integrated, Webbased, earth and biological resources database for display and further analysis within a geographic information system (GIS) framework. This GIS will provide the needed 
data and tools for furthering the understanding of the occurrence and distribution of disease-causing agents in the environment and their specific pathways of exposure in water, air, biota, and soil. To meet this objective, the following tasks will be undertaken:

\section{Data Assimilation and Integration into an Internet Map} Service: Initial efforts in 2004 will focus on cataloguing pertinent core datasets and designing and developing the architectural framework for an Internet map service (IMS). Through various partnerships with local, State, and Federal agencies in both countries, the U.S. Geological Survey has access to a variety of biologic, geologic, hydrologic, environmental, human health, cultural, and demographic datasets that will be integrated into a binational GIS. These data will be made available to public health and natural resource managers and researchers and to the public through the IMS, thus providing a geospatial foundation for analyzing causal factors between environmental conditions and human health issues, as well as for identifying data needs.

Examples of datasets to be evaluated for incorporation into the GIS include:

Biologic themes, such as contaminants in biota and identification of species and habitats at risk.

Geologic themes, such as bedrock and surficial geology, airborne geophysics, and soil and sediment geochemistry.
Hydrologic themes, such as watershed and aquifer characteristics and chemical contaminants and pathogens in source waters and treated drinking water.

Geographic themes, such as satellite imagery, land use and land cover, land-surface elevation, demographic data, and pesticide and nutrient use.

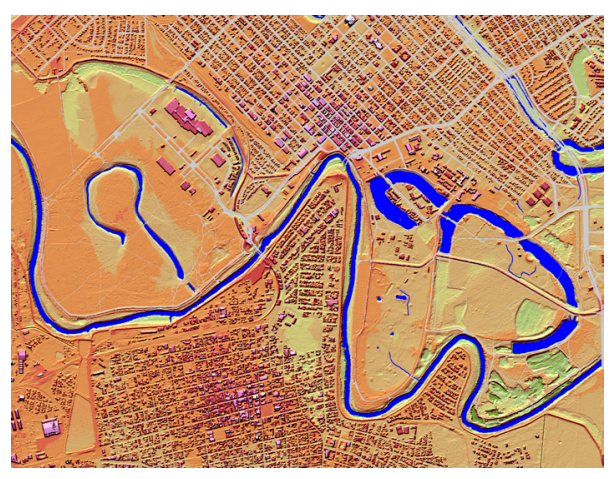

Figure 3. High-resolution digital elevation model.

The geospatial database foundation will enable scientists and public health organizations to incorporate their specific scientific datasets. Where available, integrated binational datasets will be structured in a networked database format for ease of analysis and long-term maintenance.

\section{Opportunities for Collaborative}

Science: An anticipated outcome of this project will be increased opportunities for collaboration between scientific researchers in the public health, natural resources, and environmental protection fields. Such collaborations will result in the identification of new research initiatives that ultimately will provide greater insight into the interdependence of environmental quality and human health.

However, opportunities for collaboration will only arise as a result of widespread awareness of the existence of the products from this project. Therefore, a series of stakeholder meetings in both countries will be held to introduce potential partners and end-users to the project and to solicit their support and feedback regarding the usefulness of the IMS. After the first year of the project, a fact sheet describing the availability and use of the IMS will be published.

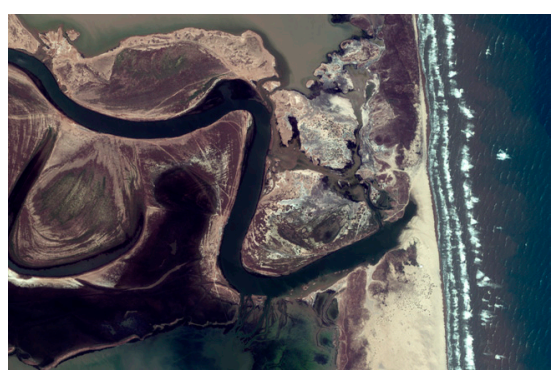

Figure 4. Satellite imagery of Rio Grande/Rio Bravo at the Gulf of Mexico.

Figures 3 and 4 courtesy of the University of Texas, Center for Space Research

For more information, contact:

Denny Buckler, (573) 876-1803

dbuckler@usgs.gov or

Eric Strom, (512) 927-3552

ewstrom@usgs.gov 